\section{COMPARING ENTROPY AND THE BISPECTRAL INDEX WITH THE RAMSAY SCORE IN SEDATED ICU PATIENTS}

Carmen Hernández-Gancedo, MD, David Pestaña, PhD, Hanna Pérez-Chrzanowska, MBBS, Elena MartinezCasanova, $M D$ and Antonio Criado, PhD
From the Servicio de Anestesia-Reanimación, Residencia General, Hospital Universitario La Paz, Paseo de la Castellana 261, 28046, Madrid, Spain.

Received 13 June 2007. Accepted for publication 9 July 2007.

Address correspondence to C. Hernández-Gancedo, MD, Servicio de Anestesia-Reanimación, Residencia General, Hospital Universitario La Paz, Paseo de la Castellana 261, 28046, Madrid, Spain. E-mail: mhgancedo@hotmail.com
Hernández-Gancedo C, Pestaña D, Pérez-Chrzanowska H, MartinezCasanova E, Criado A. Comparing entropy and the bispectral index with the Ramsay score in sedated ICU patients.

J Clin Monit Comput 2007; 21:295-302

ABSTRACT. Objective. ENTROPY ${ }^{\mathrm{TM}}$ is a new anesthetic depth monitor based on the analysis of the EEG signal. Our aim has been to evaluate sedation of intubated surgical critically ill patients by means of the Ramsay sedation score, the Bispectral index and ENTROPY ${ }^{\text {TM }}$, and to analyse the correlation between these variables. Methods. Sedation was evaluated every $15 \mathrm{~min}$ for a $1 \mathrm{~h}$ period in 50 non-paralysed postoperative critically ill, intubated patients, enrolled over a 6 month period. A 5 min steady-state period was allowed before each assessment. Both the Bispectral index and the Entropy parameters Response Entropy (RE) and State Entropy (SE), were collected before assessing the Ramsay scale. Results. Mean values for SE, RE and BIS were $53 \pm 27,60 \pm 30$, and $62 \pm 24$ respectively. The median value for the Ramsay was 6 (range 1-6). Significant correlation was found between the four variables (SE-BIS: $r=0.79, p<0.001$; RE-BIS: $r=0.80, p<0.001$; SE-Ramsay: $\rho=-0.71, p<0.001$, RE-Ramsay: $\rho=-0.72, p<0.001$; BISRamsay: $\rho=-0.78, p<0.001$; RE-SE: $r=0.98, p<0.001$ ). An overlap of BIS and Entropy values for every Ramsay score value between 4-6 was found. Conclusions. ENTROPY ${ }^{\mathrm{TM}}$, BIS and Ramsay score values correlate significantly in sedated postoperative ICU patients. ENTROPY ${ }^{\mathrm{TM}}$ does not appear superior to BIS for the assessment of sedation in this context.

KEY WORDS. intensive care, monitoring, entropy, BIS, sedation.

\section{INTRODUCTION}

Sedation is frequently required by critically ill patients [1] Appropriate sedation allows the attenuation of physiologic stress responses and contributes to better outcome. By contrast, inadequate administration of sedative agents may delay ICU discharge with the consequent increase in morbidity and cost [2].

Sedation techniques are evolving and the importance of early arousal of patients has been emphasized in the last years [3]. Excessive sedation may cause cardiovascular instability, respiratory depression, decreased gastrointestinal motility and immunosupression. Insufficient sedation, on the other hand, may result in hypertension, tachycardia, severe discomfort and accidental extubation [2]. Unfortunately, methods of monitoring the depth of sedation are scarce and not routinely included in the management of critically ill patients [4]. The bispectral index (BIS) has been proposed for this use. The BIS is an empirical variable derived from a large electroencephalogram (EEG) database, initially employed to quantify the hypnotic effects of anesthetic agents in the operating 
room [5], and several studies have considered its use in the ICU [6]. Simmons et al. [7] and Nasraway et al. [8] have not found a good correlation between various sedation scales and BIS scores in ICU patients, as opposed to other authors [9-12]. We have recently shown that the BIS appears more useful than subjective scales in those postoperative patients who require deep sedation, whenever the EMG signal and the quality signal index are considered [13].

ENTROPY ${ }^{\mathrm{TM}}$ is a new monitor based on the analysis of the EEG signal [14], and has been developed as a monitor of the anaesthetic state [15]. It calculates the spectral entropy of the EEG and measures the hypnotic component of anaesthesia. Entropy, as a physical concept, is a measure of irregularity, complexity, or amount of disorder. When entropy is measured from the EEG, disorder equals the irregularity of the EEG signal. With an awake subject, the EEG is highly irregular, and the amount of entropy is high. With increasing depth of anesthesia, the EEG turns towards more regular patterns, decreasing entropy. Datex-Ohmeda ENTROPY ${ }^{\mathrm{TM}}$ calculates spectral entropy, which has the particular advantage of being able to explicitly separate contributions to entropy from any particular frequency range. For optimal response time, the computations can be constructed in such a way that the length of the time window for each particular frequency is individually chosen. This leads to a concept known as time-frequency balanced spectral entropy [14]. The EEG is collected from the fronto-temporal region of the head. State Entropy (SE) is computed over the frequency range from 0.8 to $32 \mathrm{~Hz}$ and primarily reflects the state of the cortical activity of the patient. The Response Entropy $(\mathrm{RE})$ is computed over a frequency range from 0.8 to $47 \mathrm{~Hz}$, and includes both the EEG-dominant and EMG-dominant part of the spectrum. The RE reflects the patient's immediate response to a stimulus. A situation in which the different roles of these parameters are well demonstrated occurs during awakening, when RE rises first accompanied by the recovery of muscular activity, and seconds later is followed by a rise in the SE. In theory Entropy should prove more useful than the BIS, as the exclusion of the EMG signal in the SE prevents interferences from muscular activity and, as stated above, the RE promptly detects awakening. Both BIS and Entropy are adimensional parameters with a range of $0-100$ for BIS and RE and a range of $0-90$ for SE. The closer to 0 , the deeper the level of sedation. Our aim has been to evaluate the depth of sedation in intubated critically ill patients by means of the Ramsay sedation score, BIS ${ }^{\mathrm{TM}}$ and ENTROPY ${ }^{\mathrm{TM}}$ (RE and SE), to analyze the correlation between these variables and to see whether Entropy is more reliable than the BIS in the ICU setting.

\section{METHODS AND MATERIALS}

Fifty adult postoperative patients enrolled over a 6-month period were studied prospectively. The hospital's Ethics Committee approved the research protocol and waived the need for informed consent. Following our routine practice, different sedation regimes were used depending on the expected duration of treatment: propofol or remifentanil were administered for short (less than $48 \mathrm{~h}$ ) and midazolam/fentanyl for long-term sedation. No sedative agents were administered in 6 cases in which early extubation was expected. Pain control was achieved with i.v. morphine (1 $\mathrm{mg} / \mathrm{h}, 20$ patients in the propofol group) and/or paracetamol or metamizol, (23 postoperative patients). Doses of sedative agents were adjusted by the physician in charge whose objectives were to prevent patient-ventilator dyssynchrony while preserving hemodynamic stability. Study data were collected by the principal investigator (experienced in ICU care and experienced in assessing sedated patients) and not involved directly in the care of the patient. Patients were excluded if they presented neurological disorders, neuromuscular blockade (according to the train-of-four), hypothermia (less than $35^{\circ} \mathrm{C}$ ), history of liver dysfunction, drug and/or alcohol abuse, chronic psychotropic medication, or if adrenaline was administered, as it interferes with the bispectral index [16].

Sedation was evaluated every $15 \mathrm{~min}$ for a $1 \mathrm{~h}$ period (4 measurements per patient) after a 5 min steady-state period (absence of any kind of stimulation) in order to obtain data from different sedation levels in every patient. Sedation was assessed $2 \mathrm{~h}$ after admission to the ICU from the operating room in 26 patients. The same protocol was applied in 24 previously admitted sedated patients, so data from different postoperative stages could be obtained. Disposable BIS (BIS ${ }^{T M}$ XP, A-2000, Aspect Medical System, Newton, Ma, USA), and Entropy (ENTROPY ${ }^{\mathrm{TM}}$ Module, Datex-Ohmeda Div., Instrumentarium Corp., Helsinki, Finland) electrodes were placed on the same side of alcohol prepped forehead skin of the patients. The BIS, RE and SE data were collected before assessing the Ramsay scale. The BIS value was calculated manually on a mean average of a minute. The quality signal index was continuosly monitored, and the BIS values were only recorded when it was above $75 \%$ and the EMG signal was below 25\%. The Ramsay score (Table 1) was compared with the BIS number, SE and RE. 
Table 1. Ramsay's levels of sedation scale

\begin{tabular}{|c|c|}
\hline Level & Description \\
\hline 1 & $\begin{array}{l}\text { Patient anxious and agitated or restless } \\
\text { or both }\end{array}$ \\
\hline 2 & Patient cooperative, oriented and calm \\
\hline 3 & Patient responds to commands only \\
\hline 4 & $\begin{array}{l}\text { A brisk response to a light glabellar tap } \\
\text { or loud auditory stimulus }\end{array}$ \\
\hline 5 & $\begin{array}{l}\text { A sluggish response to a light glabellar } \\
\text { or loud auditory stimulus }\end{array}$ \\
\hline 6 & $\begin{array}{l}\text { No response to a light glabellar tap or } \\
\text { loud auditory stimulus }\end{array}$ \\
\hline
\end{tabular}

\section{Statistical analysis}

Statistical analysis was done with the SPSS for Windows system (Release 9.0). Quantitative data are described by mean, SD, median (minimum-maximum). The correlation between the Ramsay scale and the Entropy and BIS data was tested by the Spearman rank correlation coefficient. The correlation between Entropy and BIS data was assessed by the Pearson correlation coefficient. A $p$ value less than 0.05 was considered statistically significant. The concordance between the Ramsay score and SE, RE and BIS was performed with the Prediction Probability $\left(P_{\mathrm{K}}\right)$. $P_{\mathrm{K}}$ was calculated using the Somers' $\mathrm{d}$ [17]. The range for $P_{\mathrm{K}}$ is from 0 to 1 . A value of $P_{\mathrm{K}}=0.5$ means that the parameter predicts the Ramsay score not better than a 50:50 chance. A $P_{\mathrm{K}}$ value of 1.0 indicates ideal concordance.

\section{RESULTS}

Demographic data and mean arterial pressure at the first measurement are included in Table 2 . The patients had undergone cardiac $(n=7)$, general $(n=25)$, maxillofacial $(n=14)$, urological $(n=1)$, or vascular $(n=3)$ surgery. The causes for sedation were multiorgan dysfunction requiring mechanical ventilation $(n=24$, included after 24-48 $\mathrm{h}$ of admission to the ICU) or the immediate postoperative period $(n=26)$. Propofol $(2.5 \pm 1.2 \mathrm{mg} /$ $\mathrm{kg} / \mathrm{h})$ was used in 27 patients, midazolam $(0.06 \pm 0.03 \mathrm{mg} / \mathrm{kg} / \mathrm{h})$ with fentanyl $(0.94 \pm 0.52 \mu \mathrm{g} / \mathrm{kg} /$ $\mathrm{h})$ in 12 cases and remifentanil $(2.8 \pm 2.2 \mu \mathrm{g} / \mathrm{kg} / \mathrm{h})$ in five patients. In six postoperative cases no sedative agent was needed, as early extubation was expected. All patients were ventilated mechanically and did not require neuromuscular blockade. Mortality was 30\% (15/50).

Mean and median (25-75th percentiles) values for SE, RE and BIS (200 measurements) were $53 \pm 27$ and 50 (28$83), 60 \pm 30$ and 58 (31-94), and $62 \pm 24$ and 62 (41-84) respectively. The median (25-75th percentiles) values for the Ramsay was 6 (3-6). A significant correlation was found between the four variables (SE-BIS: $r=0.79$, $p<0.001$; RE-BIS: $r=0.80, p<0.001$; SE-Ramsay: $\rho=-0.71, p<0.001$, RE-Ramsay: $\rho=-0.72, p<0.001$; BIS-Ramsay: $\rho=-0.78, p<0.001$; RE-SE: $r=0.98$, $p<0.001)$. The correlation between SE, RE and BIS with the Ramsay score remained independent of the level of sedation, considering light sedation (patients responding to stimuli) as Ramsay 2-5 and deep sedation (non responding) as a Ramsay 6. The $P_{\mathrm{K}}$ (absolute values) were $0.73 \pm 0.017$ (SE-Ramsay), $0.74 \pm 0.016$ (RE-Ramsay) and $0.77 \pm 0.016$ (BIS-Ramsay).

The distribution of the SE, RE and BIS for every Ramsay score level and the plot of BIS versus Entropy values is shown in Figures 1-5. As shown in Figures 1-3, an overlap of BIS and Entropy values was found for every Ramsay score between 4 and 6. This corresponded with median values of 65,72 and 30 in the case of SE, 78, 82, 37 in the case of RE, and 80, 70 and 42 in the case of BIS for Ramsay scores of 4,5 and 6 respectively.

\section{DISCUSSION}

In this study a significant correlation between the newly developed technology of ENTROPYTM and the BIS with respect to the Ramsay score is demonstrated. However, the interpretation of isolated measurements from both monitors is difficult due to the dispersion of individual EEG-based data in every Ramsay score level.

Sedation is an important adjunct therapy for patients in the intensive care unit (ICU). Inadequate sedation can have deleterious effects for ICU patients [18], but the level of sedation is often difficult to assess in this population. In

Table 2. Demographic data. IBW: Ideal body weight

\begin{tabular}{|c|c|c|c|c|c|}
\hline & Age & Gender (male) & APACHE II & IBW (kg) & MAP (mm Hg) \\
\hline Mean \pm SD & $64 \pm 16$ & $38 / 50$ & $16 \pm 8$ & $69 \pm 10$ & $79 \pm 38$ \\
\hline
\end{tabular}

MAP: Mean arterial pressure at the first measurement. 


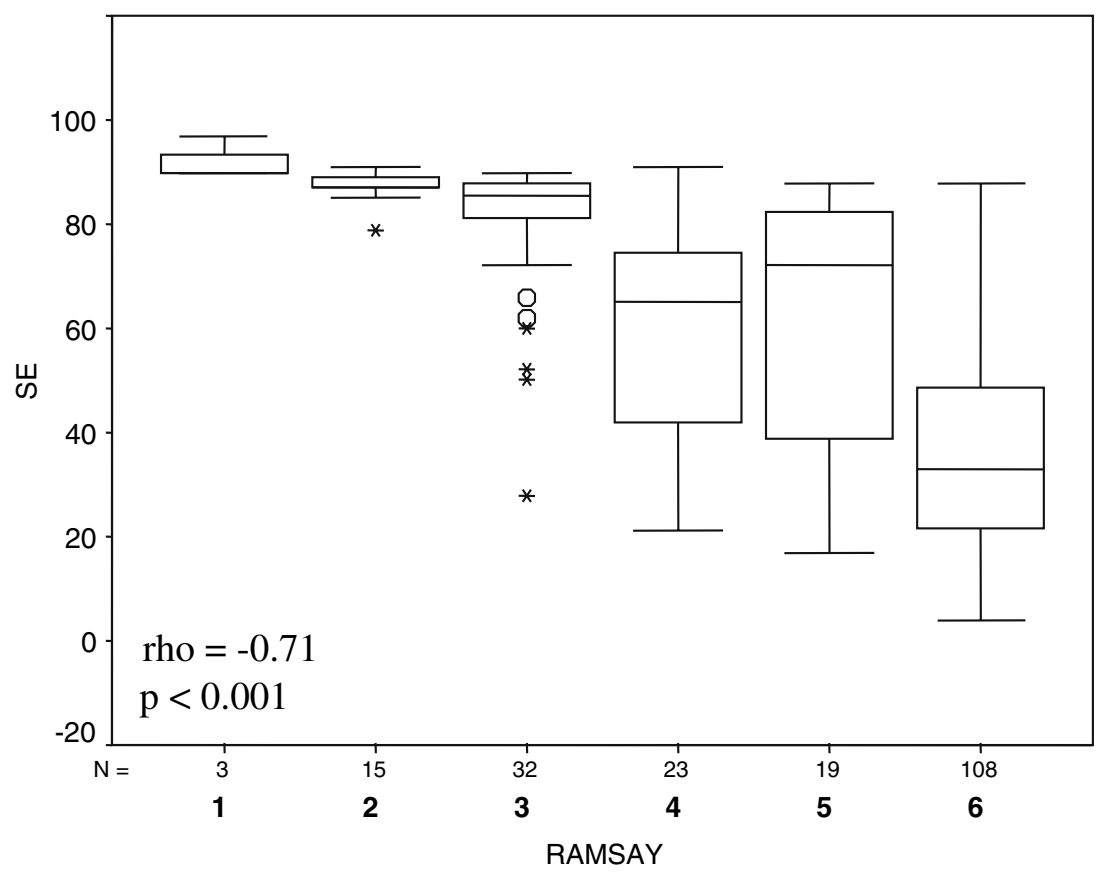

Fig. 1. Ramsay versus State Entropy (SE) box-plot. The boxes represent the 25th percentile (lower edge), the median (line across the box) and the 75 th percentile (upper edge). Upper and lower lines extend from the corresponding percentile to the highest and lowest values excluding outliers. Circles represent outliers (cases with values between 1.5 and 3 box lengths from the upper or lower edge in the box). Crosses represent extremes (cases with more than 3 box lengths).

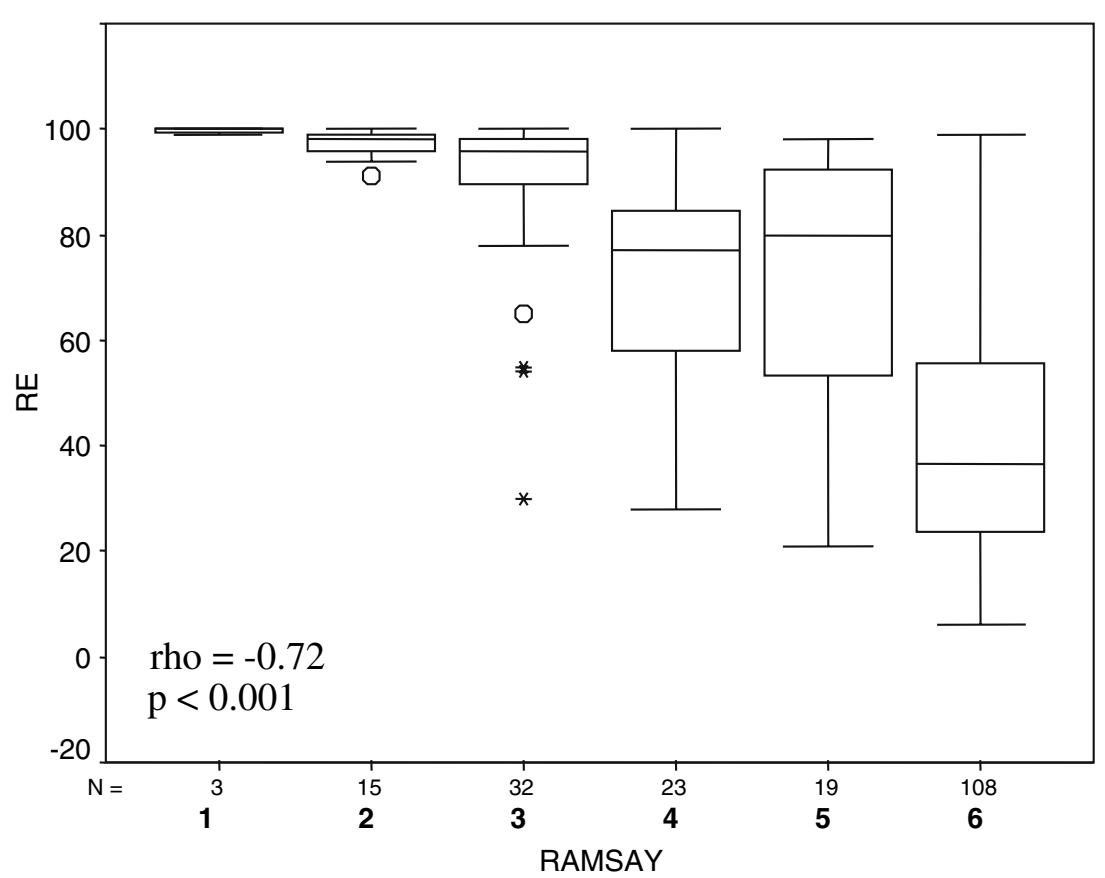

Fig. 2. Ramsay versus Response Entropy (RE) box-plot. 


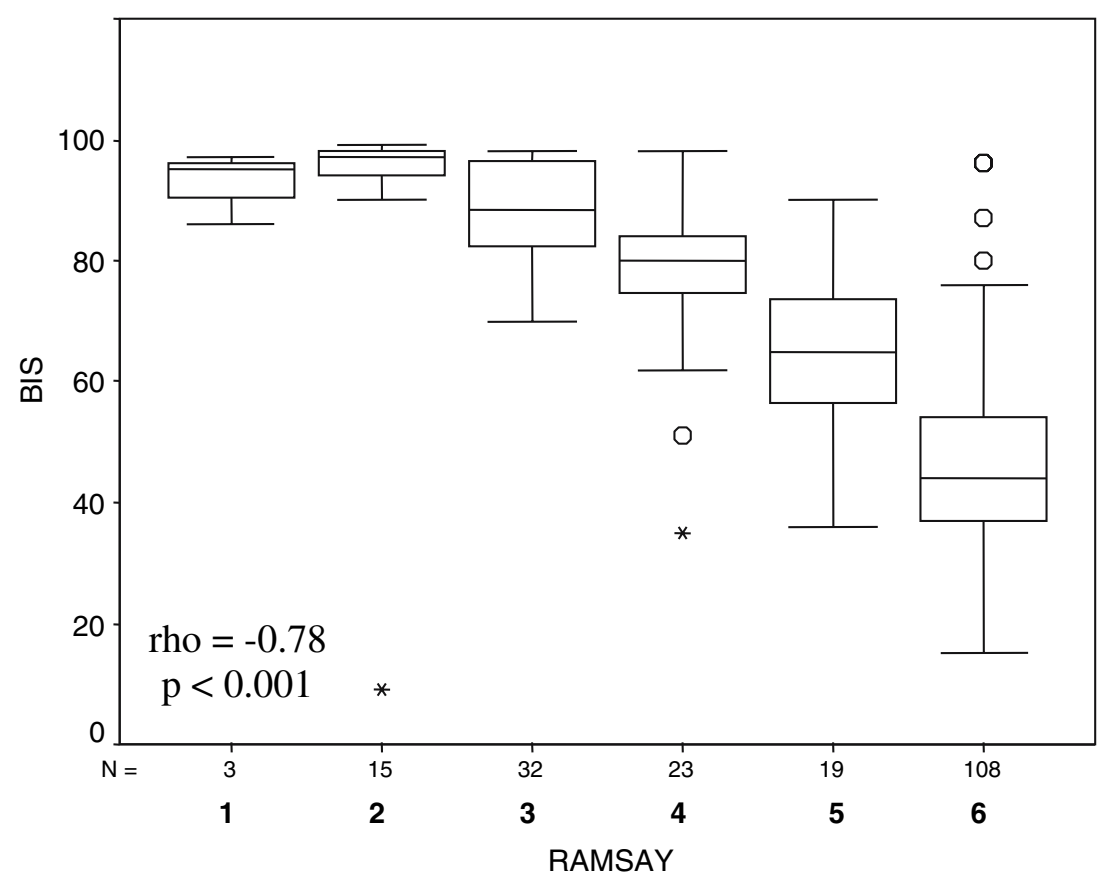

Fig. 3. Ramsay versus Bispectral Index (BIS) box-plot.

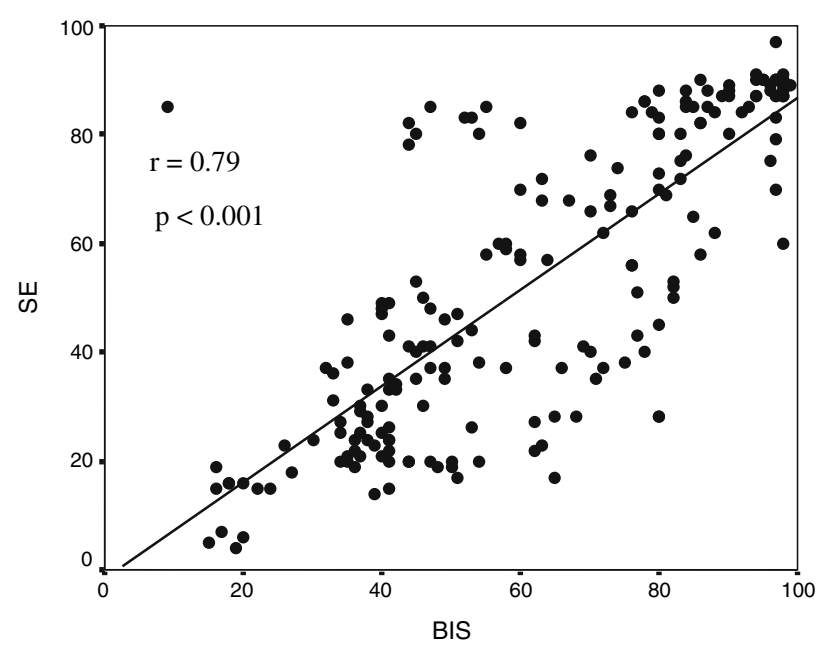

Fig. 4. Scatter plot of Bispectral Index (BIS) versus State Entropy (SE).

the last years, different subjective scoring systems have been developed, and among the various sedation scales reported, the Ramsay score is the most widely used [19-21]. The scales have several limitations such as significant interobserver variability and the impossibility of evaluating patients with neuromuscular blockade [22]. Thus, an objective measurement of the level of sedation is

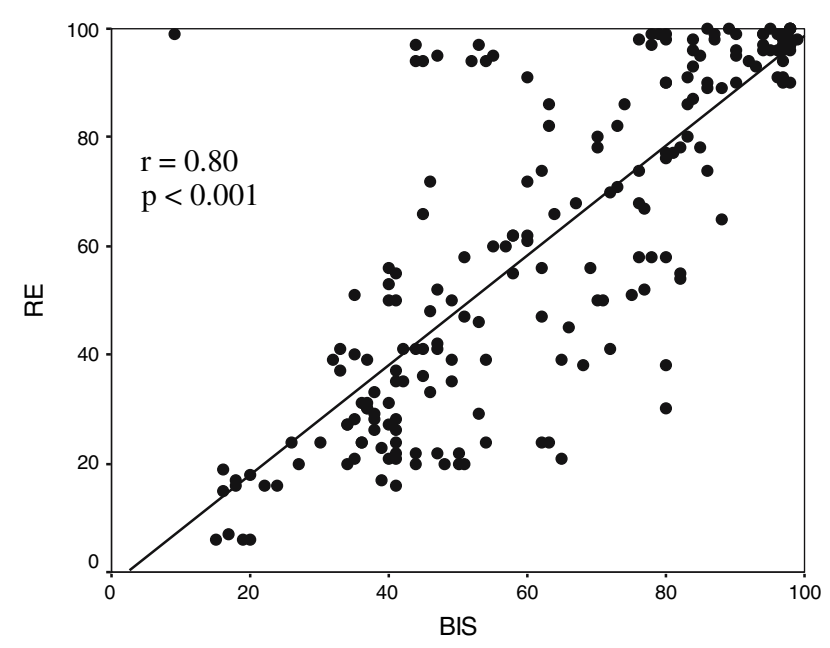

Fig. 5. Scatter plot of Bispectral Index (BIS) versus Response Entropy (RE).

necessary in order to permit increased accuracy of the assessment of sedation [23]. Various devices which analyse the EEG signal, such as the BIS and others, have been proposed for this purpose [24-26]. To our knowledge, there are no studies addressing the utility of ENTROPY ${ }^{\mathrm{TM}}$ in the ICU. 
The BIS is a number derived from the bispectral analysis of the EEG that provides information about the interactions between the cortical and the subcortical areas which change under the influence of sedative and hypnotic agents. The BIS has a range of 0 to 100 . Conscious sedation corresponds to a BIS of 70-80, and general anesthesia is reflected by a BIS in the 40-60 range [27]. Although promising, the role of the BIS in the ICU has yet to be determined. There are few studies examining its reliability in critically ill patients and, for many reasons, their results do not permit definitive recommendations [7, 8, 28-30]. Besides, many interferences common in the ICU area produce an unfavourable signal to noise ratio, yielding confounding results [31]. There have been reports of pacemakers [32] and the use of external rewarming devices resulting in increases in BIS scores [33]. In addition, physiologic movements such as eye movement or muscular activity can produce artefactual increases in the BIS score. Careful attention to the signal quality and the level of electromyographic (EMG) activity is important when the BIS is used $[8,30,34,35]$. These parameters were taken into consideration in our study.

ENTROPY ${ }^{T M}$ is a new monitor based on the analysis of the EEG signal [14]. Entropy is independent of absolute scales such as the amplitude or the frequency of the signal. In an EEG application, this is an important characteristic, as it is known that there are interindividual variations in the absolute frequencies of the EEG rhythms [15]. ENTROPYTM has been shown to be a valid indicator of the hypnotic effect of propofol, thiopental, sevoflurane and desflurane in anesthetized patients $[15,36]$. However, to our knowledge, it has never been tested in the ICU. According to our results, Entropy is similar to the BIS for assessing sedation in critically ill patients. In the present study a strong correlation between these two indexes has been found similarly to the one described in the operating room [37, 38]. Although from the clinical point of view SE should be superior to the BIS for the assessment of sedation as it excludes the frequency range involving facial muscular activity and considers only the EEG signal, it did not show this theoretical advantage in our study. This finding may be explained by the fact that most of our patients were deeply sedated, so muscular activity did not interfere with the results, even though a stronger correlation between SE and Ramsay was not found in the lightly sedated patients.

As seen in Figures 1-3, the wide dispersion of BIS and Entropy data in every Ramsay score level, especially in the 4-6 range, makes the interpretation of isolated data obtained from both monitors difficult. The dispersion is to be expected with a Ramsay level of 6 , as the subjective scales are unable to discriminate between deep sedation and cortical electric silence once the patient becomes unresponsive to light stimulation, while EEG-derived parameters go on grading cerebral electrical activity until its total suppression, beyond the levels of general anesthesia. However, a narrower range of Entropy and BIS data should have been found in both 4 and 5 Ramsay levels, when the subjective scale is more sensitive. These results coincide with others studies in which the authors observed a marked overlap between BIS and different levels of arousal assessed by the Ramsay scale [26] and RASS (Richmond Agitation-Sedation Scale) [39].

\section{Limitations of the study}

Data were not downloaded using a BIS recording software, but the BIS value was calculated manually on a mean average of a minute as previously described by different authors. This is the reason why only one of the investigators (accustomed to assessing sedated patients by means of EEG-derived techniques) was involved in the collection of the BIS data, in order to optimise this process. A careful monitoring of the quality signal index and the EMG signal also served for this purpose.

The study is observational, therefore, although most of the measurements found patients with a Ramsay score of 6 , the investigator did not take part in the adjustment of sedatives and thus a better distribution of data could not be obtained. Between 15 and 32 measurements were obtained for the rest of the Ramsay scores, (excluding Ramsay 1), so the results are still valid. There is also some concern with regard to the use of a sedation scale as a gold standard for the validation of newly developed EEG-derived technologies. The limitations of these scales have been discussed earlier. Finally, a heterogeneous group of patients and sedation regimes has been included. This represents the common practice in a postoperative ICU. Further studies investigating different subgroups of patients and sedation techniques separately will be of interest.

We conclude that ENTROPY ${ }^{\mathrm{TM}}$ appears to offer no benefits compared to the Bispectral index for the assessment of sedation in surgical ICU patients. Although a significant correlation between both EEG-derived technologies and the Ramsay score was found, further studies are required to confirm the utility of ENTROPY ${ }^{\mathrm{TM}}$ and BIS in individual critically ill patients as, according to our data, no EEG-based number can be clearly adscribed to a Ramsay level.

\section{REFERENCES}

1. Young C, Knudsen N, Hilton A, Reves JG. Sedation in the intensive care unit. Crit Care Med 2000; 28: 854-866. 
2. Sydow M, Neumann P. Sedation for the critically ill. Intensive Care Med 1999; 25: 634-636.

3. Shapiro BA, Warren J, Egol AB, Greenbaum D, Jacobi J, Nasraway S, Schein R, Spevetz A. Practical parameters for intravenous analgesia and sedation for adult patients in the intensive care unit: an executive summary. Crit Care Med 1995; 23: 1596-1600.

4. De Jonghe B, Cook D, Appere-De-Vecchi C, Guyatt G, Meade $\mathrm{M}$, Outin $\mathrm{H}$. Using and understanding sedation scoring systems: a systematic review. Intensive Care Med 2000; 26: 275-285.

5. Sebel PS, Lang E, Rampil IJ, White PF, Cork R, Jopling M, Smith NT, Glass PS, Manberg P. A multicenter study of bispectral electroencephalogram analysis for monitoring anesthetic effect. Anesth Analg 1997; 84: 891-899.

6. Walsh TS, Ramsay P, Kinnunen R. Monitoring sedation in the intensive care unit: can "black boxes" help us?. Intensive Care Med 2004; 30: 1537-1543.

7. Simmons LE, Riker RR, Prato BS, Fraser GL. Assessing sedation during intensive care unit mechanical ventilation with the bispectral index and the sedation-agitation scale. Crit Care Med 1999; 27: 1499-1504.

8. Nasraway SA, Wu EC, Kelleher RM, Yasuda CM, Donnelly AM. How reliable is the bispectral index in critically ill patients? A prospective, comparative, single-blinded observer study. Crit Care Med 2002; 30: 1483-1487.

9. Deogaonkar A, Gupta R, DeGeorgia M, Sabharwa V, Gopakumaran B, Schubert A, Provencio J. Bispectral index monitoring correlates with sedation scales in brain-injured patients. Crit Care Med 2004; 32: 2403-2406.

10. Mondello E, Siliotti R, Noto G, Cuzzocrea E, Scollo G, Trimarchi G, Saverio F. Bispectral index in ICU: correlation with Ramsay score on assessment of sedation level. J Clin Monit 2002; 17: 271-277.

11. Riker R, Fraser G, Simmons L, Wilkins M. Validating the sedation-agitation scale with the bispectral index and visual analog scale in adult ICU patients after cardiac surgery. Int Care Med 2001; 27: 853-858.

12. Frenzel D, Greim C-A, Sommer C, Bauerle K, Roewer N. Is the bispectral index appropriate for monitoring the sedation level of mechanically ventilated surgical ICU patients?. Intensive Care Med 2002; 28: 178-183.

13. Hernández-Gancedo C, Pestaña D, Peña N, Royo C, PérezChrzanowska H, Criado A. Monitoring sedation in critically ill patients: bispectral Index versus the Ramsay and OAA/S scales. Eur J Anaesthesiol 2006; 23: 649-653.

14. Viertiö-Oja H, Maja V, Sarkela M, Talja P, Tenkanen N, Tolvasen- Laakso H, Paloheimo M, Vakkuri A, Yli-Hankala A, Merilainen P. Description of the Entropy ${ }^{\mathrm{TM}}$ algorithm as applied in the Datex-Ohmeda S/5 $5^{\mathrm{TM}}$ Entropy Module. Acta Anaesthesiol Scand 2004; 48: 154-161.

15. Bruhn J, Rópcke H, Hoeft A. Approximate Entropy as an electroencephalographic measure of anesthetic drug effect during desflurane anaesthesia. Anesthesiology 2000; 92: 715-726.

16. Andrzejowski J, Sleigh JW, Johnson AT, Sikiotis L. The effect of intravenous epinephrine on the bispectral index and sedation. Anaesthesia 2000; 55: 761-763.

17. Smith WD, Dutton RC, Smith NT. Measuring the performance of anesthetic depth indicators. Anesthesiology 1996; 84: $38-51$.
18. Shafer A. Complications of sedation with midazolam in the intensive care unit and a comparision with other sedative regimens. Crit Care Med 1998; 26: 947-956.

19. Ramsay MAE, Savege TM, Simpson BRJ, Goodwin R. Controlled sedation with alphaxalone-alphadolone. B Med J 1974; 2: 656-659.

20. Soliman HM, Mélot C, Vincent J-L. Sedative and analgesic practice in the intensive care unit: the results of a European survey. Br J Anaesth 2001; 87: 186-192.

21. Payen, JF, Chanques, G, Mantz, J, Hercule, C, Auriant, Leguillou JL, Binhas M, Genty C, Rolland C, Bosson JL. Current practices in sedation and analgesia for mechanically ventilated critically ill patients. Anesthesiology 2007;106: 687-695.

22. Hansen-Flaschen J, Coven J, Polomano RC. Beyond the Ramsay scale: need for a validated measure of sedating drug efficacy in the intensive care unit. Crit Care Med 1994; 22: 732-733.

23. Jacobi J, Fraser GL, Coursin DB, Riker R, Fontaine D, Wittbrodt E, Chalfin D, Masica M, Bjerke H, Coplin W, Crippen D, Fuchs B, Kelleher R, Maric P, Nasraway S, Murray M, Peruzzi W, Lumb P. Clinical practice guidelines for the sustained use of sedatives and analgesics in the critically ill adult. Crit Care Med 2002; 30: 119-141.

24. Shearer ES, ÓSullivan EP, Hunter JM. An assessment of the Cerebrotrac 2500 for continuos monitoring of cerebral function in the intensive care unit. Anaesthesia 1991; 46: 750-755.

25. Spencer EM, Green JL, Willatts SM. Continuous monitoring of depth of sedation by EEG spectral analysis in patients requiring mechanical ventilation. Br J Anaesth 1994; 73: 649-654.

26. De Deyne C, Struys M, Decruyenaere J, Creupelandt J, Hoste E, Colardyn F. Use of continuous bispectral EEG monitoring to assess depth of sedation in ICU patients. Intensive Care Med 1998; 24: 1294-1298.

27. Sennholz G. Bispectral analysis technology and equipment. Minerva Anestesiol 2000; 66: 386-388.

28. Brocas E, Dupont H, Paugam-Burtz C, Servin F, Mantz J, Desmonts J-M. Bispectral index variations during tracheal suction in mechanically ventilated critically ill patients: effect of an alfentanil bolus. Intensive Care Med 2002; 28: 211-213.

29. Walder B, Suter P, Romand J. Evaluation of two processed EEG analyzers for assessment of sedation after coronary artery bypass grafting. Intensive Care Med 2001; 27: 107-114.

30. Vivien B, Di Maria S, Ouattara A, Langeron O, Coriat P, Riou B. Overestimation of bispectral index in sedated intensive care unit patients revealed by administration of muscle relaxant. Anesthesiology 2003; 99: 9-17.

31. Chan MT, Gin T. What does the bispectral EEG index monitor?. Eur J Anaesthesiol 2000; 17: 146-148.

32. Gallager JD. Pacer-induced artifact in the bispectral analysis for the electroencephalogram. Anesthesiology 1999; 90: 636 .

33. Guignard B, Chauvin M. Bispectral Index increases and decreases are not always signs of inadequate anesthesia. Anesthesiology 2000; 92: 903.

34. Bruhn J, Bouillon T, Shafer S. Electromyographic activity falsely elevates the bispectral index. Anesthesiology 2000; 92: 1485-1487.

35. Renna M, Wigmore T, Mofeez A, Gillbe C. Biassing effect of the electromyogram on BIS: a controlled study during highdose fentanyl induction. J Clin Monit 2002; 17: 377-381. 
36. Vakkuri A, Yli-Hankala A, Talja P, Mustola S, Tolvanen-Laakso $\mathrm{H}$, Sampson T, Viertiö-Oja H. Time-frequency balanced spectral entropy as a measure of anesthetic drug effect in central nervous system during sevofluorane, propofol, and thiopental anesthesia. Acta Anaesthesiol Scand 2004; 48: 145-153.

37. White P, Tang J, Romero G, Wender R, Naruse R, Sloninsky A, Kariger R. A comparison of state and response entropy versus bispectral index values during the perioperative period. Anesth Analg 2006; 102: 160-167.
38. Schmidt G, Bischoff P, Standl T, Hellstern A, Teuber O, Schulte J. Comparative evaluation of the Datex-Ohmeda S/5 entropy module and the bispectral index monitor during propofol-remifentanil anesthesia. Anesthesiology 2004; 101: 1283-1290.

39. Ely. Consciousness monitoring in ventilated patients: bispectral EEG monitors arousal not delirium. Intensive Care Med 2004; 30: $1537-1543$. 